\title{
"Non-traditional" stable isotope analysis as tracer so identify sources and sinks of inorganic contaminants in riverine environments
}

\author{
T. ZIMMERMANN ${ }^{1}$, O. KLEIN ${ }^{1,2}$, A. REESE ${ }^{1,2}$, \\ A.F. MOHAMED ${ }^{3}$, M.E. WIESER ${ }^{3}$, J. IRRGEHER ${ }^{3}$, \\ D. PRÖFROCK ${ }^{1}$
}

${ }^{1}$ Helmholtz-Zentrum Geesthacht, Institute of Coastal Research, Geesthacht, Germany

${ }^{2}$ Universität Hamburg, Department of Chemistry, Hamburg, Germany

${ }^{3}$ University of Calgary, Department of Physics and Astronomy, Calgary, Canada

${ }^{4}$ Montanuniversität Leoben, Department General, Analytical and Physical Chemistry, Leoben, Austria

Environmental monitoring of complex ecosystems requires reliable and sensitive techniques in order to identify the source, fate and sink of inorganic, anthropogenic contaminants in e.g. aquatic ecosystems.

This contribution presents large scale isotopic data of $\mathrm{B}, \mathrm{Zn}, \mathrm{Sr}, \mathrm{Nd}$ and $\mathrm{Pb}$, measured via MC ICP-MS, for water and sediment samples of two major Europaen rivers (Rhine, Elbe). The aim was to apply stable isotope analysis as new, potential tracer to elucidate processes involving anthropogenic metal emissions, as well as to characterize the catchment areas for further studies.

Within this context we analyzed the $\mathrm{Zn}$ isotopic composition, to potentially trace anthropogenic $\mathrm{Zn}$ emission on a large regional scale. The combination of dissolved $\mathrm{B}$ and $\mathrm{Sr}$ isotopic compositions may be used to distinguish different inputs into river systems, and provide insight into possible sources of B inputs. Furthermore, $\mathrm{Sr}, \mathrm{Nd}$ and $\mathrm{Pb}$ isotope data can give valuable information for source attribution of sediment masses

Our results clearly indicate that the exclusive focus on the quantitative analysis of metal contamination within the context of environmental research provides only limited information. The progress achieved in isotope ratio analysis over the last decade therefore opens valuable additional information for environmental scientists. 